\title{
COMPARATIVE EVALUATION OF ONSET, DURATION AND SAFETY BETWEEN MIDAZOLAM, DEXMEDETOMIDINE SEDATION AND THEIR COMBINATION IN PRESCHOOLERS: A RANDOMIZED CLINICAL TRIAL
}

\author{
Amira A. El-Khatib ${ }^{1 *} M S c$, Nadia A. Wahba ${ }^{2} P h D$, Karin ML. Dowidar ${ }^{2} P h D$, Tamer
} AM. Ghoneim ${ }^{3} P h D$

\begin{abstract}
INTRODUCTION: Dental anxiety is a global problem in pediatric dentistry. Moderate sedation is an acceptable option for uncooperative preschoolers dental patients.

OBJECTIVES: To compare midazolam (MDZ), dexmedetomidine (DEX) and their combination (DEX/MDZ) as sedative drugs for preschoolers undergoing dental treatment regarding onset, duration and safety of sedation.

MATERIALS AND MERTHODS: The study was a three-arm randomized clinical trial with a parallel design. Seventy-two healthy uncooperative preschoolers were selected from the Faculty of Dentistry, Alexandria University, Egypt. The participants were randomly allocated into, control group received $0.5 \mathrm{mg} / \mathrm{kg} \mathrm{MDZ}$, study group I received $5 \mu \mathrm{g} / \mathrm{kg} \mathrm{DEX}$, and study group II received $0.3 \mathrm{mg} / \mathrm{kg} \mathrm{MDZ}$ followed by $3 \mu \mathrm{g} / \mathrm{kg}$ DEX. Each child received quadrant treatment. Time until optimum sedation and recovery were recorded. Vital signs were recorded throughout the treatment session.

RESULTS:

All children were comparable regarding demography, physical status and baseline vital signs (blood pressure, heart rate, and oxygen saturation). There was a statistically significant difference regarding onset and duration of the effect of sedative drugs $(\mathrm{P}=<0.001)$. Dexmedetomidine had the most delayed onset of action (17.08 $\pm 5.88 \mathrm{~min})$, while DEX/ MDZ had the longest duration of action (68.13 \pm 17.12$)$. There was a significant decrease in blood pressure throughout the sedation session for all children. Children who were sedated with DEX and DEX/MDZ had a significant decrease in heart rate than children sedated with MDZ. No statistically significant effect of drugs on oxygen saturation levels was
\end{abstract} recorded.

CONCLUSIONS:

Midazolam, Dexmedetomidine and their combination are safe drugs during moderate sedation for children undergoing dental treatment. The protocol of the study was registered and posted on the ClinicalTrials.gov public website. ClinicalTrials.gov Identifier: NCT03827408. KEYWORDS: Midazolam, Dexmedetomidine, Moderate sedation, Dental sedation, Preschool children.

1 Assistant lecturer of Pediatric Dentistry, Faculty of Dentistry Kafr elsheikh University, Egypt

2 Professor of Pediatric and Dental Public Health Department, Faculty of Dentistry, Alexandria University, Egypt

3 Lecturer of Anesthesia, Faculty of Medicine, Alexandria University, Egypt.

*Corresponding author:

E-mail: Amira Elkhateb@den.kfs.edu.ed

\section{INTRODUCTION}

Dental fear and anxiety are widely recognized problems affecting young children, and are considered the global barrier in pediatric dentistry (1). However, the oral health of young children specially preschoolers can have a significant effect on their wellbeing and their families welfare, and affect their quality of life (2). A debate always exists over the best behavioral management technique used with them, since the basic behavior management techniques may not offer the efficiency and safety required (3). Moderate sedation is considered an option for treating preschoolers (3, 4) . The best results would be obtained by selecting the lowest dose of the drug with the highest therapeutic index, and a wide safety margin (5). This would involve understanding of the pharmacodynamics and pharmacokinetics of the sedative drug used, careful pre- sedation airway evaluation, and appropriate monitoring and emergency equipment (5).

Midazolam is a short-acting benzodiazepine, and one of the classical pediatric procedural sedative drugs (6). It is an effective anxiolytic, muscle relaxant, and amnesic drug (7). The effective dose of MDZ is between $0.25-0.5 \mathrm{mg} / \mathrm{kg}$ in children (7). Lately, DEX has been introduced clinically for procedural sedation (8). Dexmedetomidine has anxiolytic, sympatholytic, and analgesic effects $(6,8)$. An important feature of DEX-based sedation is to maintain spontaneous ventilation (6). This makes DEX an interesting safe alternative sedative drug $(6,9)$. The most clinically effective dose of DEX is $5 \mu \mathrm{g} / \mathrm{kg}(10)$.

In a systematic review by Barends et al. (6), comparing the efficacy and safety of DEX and MDZ when used for procedural sedation, DEX had advantages over 
MDZ in terms of sedation level, and analgesia. However, the few studies makes it difficult to conclude and approve the exclusive usage of DEX for any type of dental procedures(6) . The onset time of MDZ is 10-15 minutes (11), with highest plasma level is reached after 30 minute (7). This would allow an average of 30 minutes work which is suitable for dental procedural sedation (7). Moreover, the short half-life of MDZ decreases the hangover effects when used as a sole sedative drug (11). Kumari et al. (12), concluded that oral MDZ had faster onset of sedation to oral DEX. Similarly, Oriby et al. (13), found that premedication with intranasal 2 $\mu \mathrm{g} / \mathrm{kg}$ DEX was a rapid and effective alternative in children undergoing dental rehabilitation when compared to $0.2 \mathrm{mg} / \mathrm{kg}$ intranasal MDZ. The onset of sedation for intranasal DEX was between 20-40 min and significantly longer than intranasal MDZ, which was around 10-25 min, but intranasal DEX allowed for significantly shorter time for induction when used as premedication than intranasal MDZ (14).

In dentistry, the addition of MDZ to DEX may be an appropriate combination (15). To our best knowledge, few studies were conducted on pediatric dental sedation using nebulized MDZ versus DEX and a combination of both drugs. The study aims to evaluate and compare nebulized MDZ, DEX and their combination as procedural sedative drugs for preschoolers undergoing dental treatment in terms of onset and duration of sedation and safety in terms of vital signs. The null hypothesis would be that there is no difference between the effect of MZD, DEX, or their combination regarding the onset, duration and safety during sedation for preschool children.

\section{MATERIALS AND METHODS}

Ethical approval for the study was obtained from the Dental Research Ethics Committee, Faculty of Dentistry, Alexandria University (IRB 00010556 - IORG 0008839) and registered on clinicaltrials.gov (Trial ID: NCT03827408). Parents of all children were asked to provide an informed written consent for the procedure and publication, after thorough explanation of the study aims. The study was a three-arm randomized clinical trial with a parallel design following the CONSORT guidelines (16). The PICO question was: do pre-schoolers undergoing procedural sedation (Population: P) with Midazolam (Intervention: I), compared to Dexmedetomidine or their combination (Comparison: C) show better onset, duration of sedation, and safety (outcome: $\mathrm{O}$ )?

The study was conducted on preschoolers (aged 4-6 years) attending the outpatient clinic of the Pediatric Dentistry and Dental Public Health Department, Faculty Of Dentistry, Alexandria University, in whom all basic behavior guidance techniques had failed in providing essential dental care. The sample size was calculated using Gpower version 3.1.9.2 (17). Based on the primary outcome from a previous study by Zanaty \& Metainy (1). A sample size of 24 per group (number of groups = 3) was the minimum enough required sample.

Eighty-five children were examined for eligibility; seventy-two were selected and were randomly divided into three groups. The study included 44 males and 28 females.
Healthy preschoolers classified according to American Society Anesthesiologists Physical Status Classification (ASA I or II physical status) (18), with no previous dental experience (19) were enrolled in the study. Children participated showed definitely negative and negative behavior according to Frankl behavior rating scale ( score 1 or 2) (20), who required dental intervention under local anesthesia for not more than 30 minutes (21). Those who had a history of neurological or cognitive alterations (21), or mouth breathers (21) were excluded. Then children who were enrolled in the study were randomly assigned to one of the three groups using a computer generated list of random numbers. Allocation was performed by using permuted block technique, where allocation ratio is intended to be equal.

The study was a triple blind, the researcher, statistician and participants were blind, only the supervisor and the anaesthesiologist were aware of the allocation group. Children enrolled in the study were sedated using a nebulizer, where control group received $0.5 \mathrm{mg} / \mathrm{kg} \mathrm{MDZ}$, study group I received $5 \mu \mathrm{g} / \mathrm{kg} \mathrm{DEX}$, and study group II received $3 \mu \mathrm{g} / \mathrm{kg}$ DEX followed by $0.3 \mathrm{mg} / \mathrm{kg} \mathrm{MDZ}$. The procedural sedation sessions took place at the "Special Needs Clinic" of Pediatric Dentistry and Dental Public Health Department.

On the day of sedation, patients were scheduled to arrive one hour before treatment, to assess the health of the child, and to ensure compliance with the pre-sedation instructions (22). Child's body weight and baseline vital signs were recorded. According to the randomization plan, the drugs planned to be used during the procedural session were freshly prepared from parenteral forms. The proper designated drug dosage; calculated from the body weight were diluted into equal final volume by adding distilled water (23), and divided equally into two identical insulin syringes to maintain operator blinding. In case of using a single sedative drug " $0.5 \mathrm{mg} / \mathrm{kg}$ MDZ (24), or $5 \mu \mathrm{g} / \mathrm{kg}$ DEX (10)", the dosage was divided into two syringes. In case of combing two sedative drugs " $3 \mu \mathrm{g} / \mathrm{kg}$ DEX followed by 0.3 $\mathrm{mg} / \mathrm{kg}$ MDZ.(25)”, each drug was loaded in a different syringe. Dexmedetomidine was loaded in syringe 1 , to be nebulized first, and MDZ was loaded in syringe 2.

Once satisfactory sedation level was reached (according to Wilton et al sedation scale) (26) the time of onset of sedation was recorded (27), and the dental operative treatment was started. All vital signs including systolic blood pressure (SBP), diastolic blood pressure (DBP), heart rate (HR), and oxygen saturation $\left(\mathrm{SaO}_{2}\right)$ were monitored and recorded at baseline, after nebulizing first drug dosage, after nebulizing second drug dosage, and before discharge (28). The safety of each drug was assessed according to the effect on vital signs (28). After the completion of the operative dental procedures, the child was monitored for recovery and discharge criteria according to American Academy of Pediatric Dentistry (AAPD) guidelines (22), the time of the duration of sedation was recorded (27). Before discharge, postoperative care instructions concerning the dental operative procedure were given to the parents. The parents were instructed to assist the child during walking and to observe the child during the 
rest of the day (4), After 24 hours: Parents were contacted via telephone to check upon the child regarding the postoperative effects of sedation.

The study outcomes were (i) Onset of Sedation: the time recorded from drug administration until the onset of optimum sedation stage (27). (ii) The duration of sedation: the time was recorded from onset of optimum sedation stage until the time of meeting the discharge criteria (27) . (iii) Safety of sedative drugs in terms of vital signs including (HR, SaO2, SBP, and DBP) recorded at baseline, after nebulizing first drug dosage, after nebulizing second drug dosage, and before discharge (28).

\section{STATISTICAL ANALYSIS:}

Statistical analysis was carried out using The Statistical Package for the Social Sciences (SPSS for windows, version 23.0, Inc. Chicago, IL, USA). Significance level was set at the $5 \%$ level. Descriptive statistics were displayed as mean, standard deviation for quantitative variables; Normality was checked for all variables using descriptive statistics, and Kolmogorov-Smirnov test of normality. Mean and Standard Deviation (SD) were calculated for all quantitative variables. One-way ANOVA test was used to compare age among the 3 study groups. Dichotomous variables were compared among the 3 groups using Chi square test (gender). For quantitative non-normally distributed variables (onset and duration of sedation), Kruskal - Wallis Test was used to compare the 3 groups followed by post-hoc tests with multiple comparisons using Bonferroni adjustment for significant differences. Repeated measures ANOVA were used for comparing variables among the 3 study groups at different time points (Systolic blood pressure, diastolic blood pressure, heart rate, and oxygen saturation).

\section{RESULTS}

All children enrolled in the study completed the protocol, A CONSORT diagram showing the study protocol after 24 hours follow-up is presented in Figure 1. The groups were comparable in terms of demographic data, type and duration of treatment (Tables 1 and 3). There was no statistically significant difference between the three groups regarding age and sex $(\mathrm{P}=0.06,0.47$, Table 1$)$. Each child received quadrant treatment; type and duration of treatment were comparable for all groups (Table 1). The vital signs (SBP, $\mathrm{DBP}, \mathrm{HR}, \mathrm{SaO}_{2}$ ) for all children were comparable at baseline (Table 3).

Both the onset and duration of the effect of sedative drugs showed a statistically significant difference $(\mathrm{P}=<0.001$, Table 2). Dexmedetomidine had significantly delayed onset of action with a mean time of (17.08 \pm 5.88 min) than MDZ (11.88 $\pm 5.48 \mathrm{~min})$ and DEX/MDZ (8.33 \pm $4.34 \mathrm{~min}$ ) (Table 2). The combination of DEX/MDZ had the longest duration of action (68.13 \pm 17.12$)$ compared to MDZ $(38.33 \pm 14.50 \mathrm{~min})$ and DEX (48.33 $\pm 15.30 \mathrm{~min})$ (Table 2).

As for the blood pressure (SBP, DBP) there was a statistically significant effect of time rather than drug type within three groups ( $\mathrm{P}<0.001$, Table 3 ). A significant decrease in SBP throughout the sedation session was detected $(\mathrm{P}<0.001$, Figure $2 \mathrm{a})$. Similarly, there was a significant decrease DBP throughout the sedation session $(\mathrm{P}<0.001$, Figure 2b.) But there was no statistically significant effect of drug type on neither SBP nor DBP ( $\mathrm{P}=0.64,0.31$, Table 3).

As well as there was no statistically significant difference neither between the baseline and postoperative mean SBP $(102.04 \pm 10.25,103.25 \pm 7.02,104.54 \pm 8.27)$ $(100.75 \pm 9.96,102.50 \pm 8.90,108.17 \pm 15.17)$ nor baseline and postoperative DBP $(65.71 \pm 8.63,69.54 \pm 7.18,68.33 \pm$ $7.87)(64.71 \pm 7.82,64.63 \pm 6.45,68.04 \pm 9.56)$ respectively among three groups (Table 3 ).

Regarding the heart rate, there was a significant decline in HR detected through the sedation sessions. Both time and drug type had statistical significant effect on the mean HR $(\mathrm{P}<0.001$, Table 3 , figure 3$)$ As for oxygen saturation, there was no statistically significant difference for the effect of neither time nor sedative drug on the percentage of $\mathrm{O}_{2}$ saturation during the sedation session (Table 3).
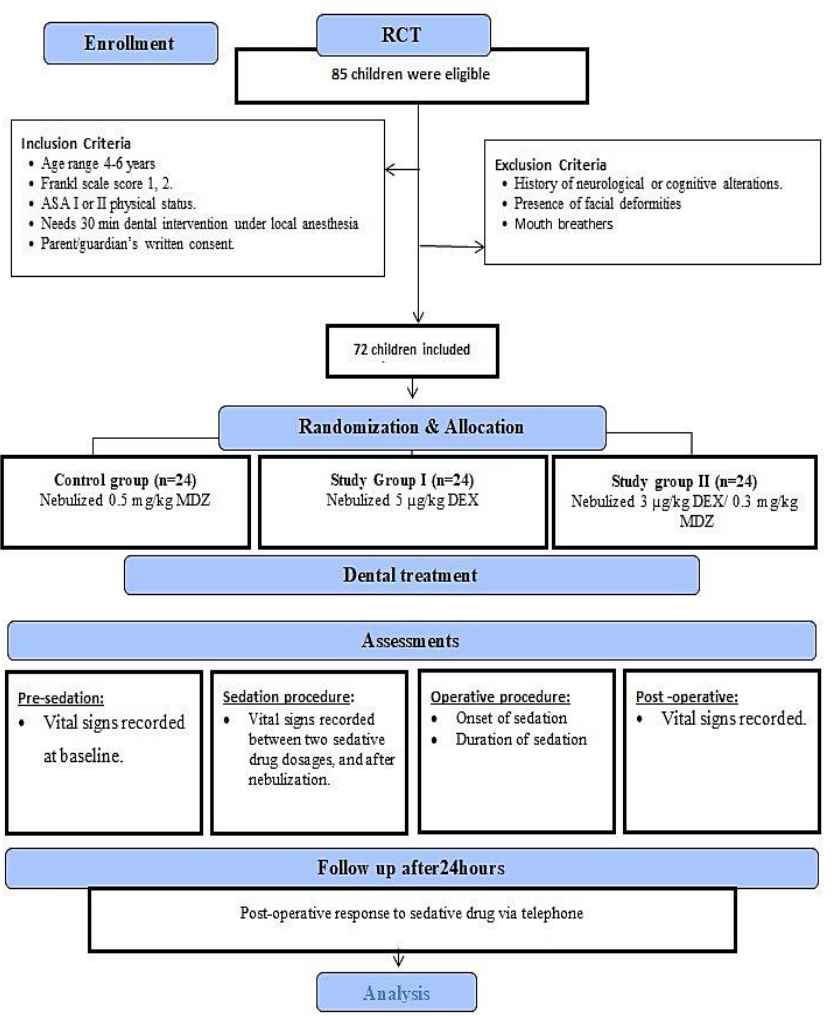

Research design flow chart according to CONSORT

Figure 1:

CONSORT diagram showing the study protocol after 24 hours follow-up.

MDZ: Midazolam

DEX: Dexmedetomidine

DEX/MDZ: Dexmedetomidine-Midazolam combination 


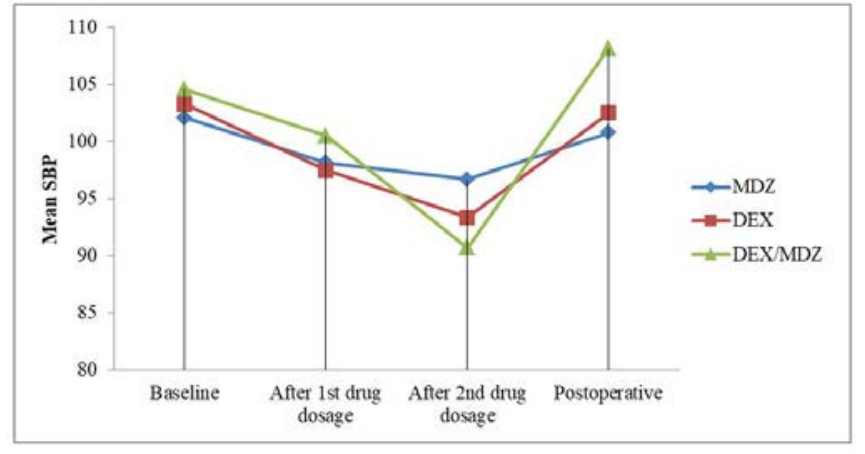

Figure 2a:

Comparison of the effect of sedative drugs on systolic blood pressure among study groups.

MDZ: Midazolam

DEX: Dexmedetomidine

DEX/MDZ: Dexmedetomidine-Midazolam combination

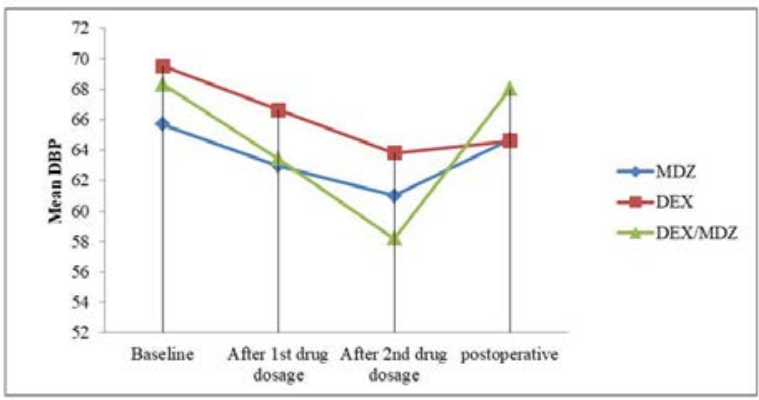

Figure 2b:

comparison of the effect of sedative drugs on diastolic blood pressure among study groups.

MDZ: Midazolam

DEX: Dexmedetomidine

DEX/MDZ: Dexmedetomidine-Midazolam combination

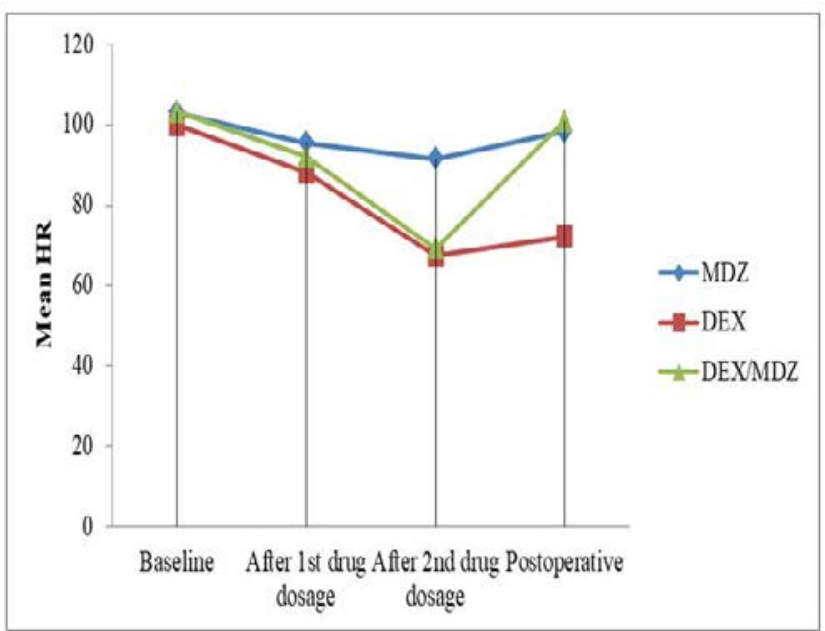

Figure 3:

Comparison of the effect of sedative drugs on heart rate among study groups.

MDZ: Midazolam

DEX: Dexmedetomidine

DEX/MDZ: Dexmedetomidine-Midazolam combination
Table1: Demographic data, and type of treatment among study groups:

\begin{tabular}{|c|c|c|c|c|c|}
\hline & & MDZ & DEX & $\begin{array}{l}\mathrm{DEX} / \mathrm{M} \\
\mathrm{DZ}\end{array}$ & $\begin{array}{l}\text { Test } \\
\text { Valu } \\
\mathrm{e} \\
\mathrm{P} \\
\text { Valu } \\
\mathrm{e}\end{array}$ \\
\hline \multicolumn{2}{|c|}{ Age (mean \pm SD) } & $\begin{array}{ll}4.08 & \pm \\
0.41 & \end{array}$ & $\begin{array}{l}4.33 \pm \\
0.52\end{array}$ & $\begin{array}{l}4.40 \quad \pm \\
0.47\end{array}$ & $\begin{array}{l}£= \\
2.99 \\
0.06\end{array}$ \\
\hline \multirow{2}{*}{$\begin{array}{l}\text { Gender } \\
(\mathrm{n}= \\
24)\end{array}$} & & $\begin{array}{l}14 \\
(58.3 \%)\end{array}$ & $\begin{array}{l}13 \\
(54 . \\
2 \%)\end{array}$ & $\begin{array}{l}17 \\
(70.8 \%)\end{array}$ & \multirow{2}{*}{$\begin{array}{l}\mathrm{X} 2= \\
1.52 \\
0.47\end{array}$} \\
\hline & & $\begin{array}{l}10 \\
(41.7 \%)\end{array}$ & $\begin{array}{l}11 \\
(45 . \\
8 \%)\end{array}$ & $\begin{array}{l}7 \\
\text { (29.2\%) }\end{array}$ & \\
\hline \multirow{4}{*}{$\begin{array}{l}\text { treatm } \\
\text { nt } \\
\text { (n } \\
24)\end{array}$} & & & $\begin{array}{l}5 \\
(20.8 \% \\
)\end{array}$ & $\begin{array}{l}4 \\
(16.7 \%)\end{array}$ & $\begin{array}{l}\mathrm{F} \\
=0.2 \\
4 \\
0.91\end{array}$ \\
\hline & $\begin{array}{l}\text { Stainle } \\
\text { steel } \\
\text { crown }\end{array}$ & & & $\begin{array}{l}1 \\
(4.16 \%)\end{array}$ & $\begin{array}{l}F \\
=0.6 \\
6 \\
0.35\end{array}$ \\
\hline & $\begin{array}{l}\text { yulpotc } \\
\text { ystainle } \\
\text { steel } \\
\text { crown }\end{array}$ & $\begin{array}{l}22 \\
(91.67 \\
\%)\end{array}$ & $\begin{array}{l}24 \\
(100\end{array}$ & $\begin{array}{l}24 \\
(100 \%)\end{array}$ & $\begin{array}{l}\mathrm{X} 2= \\
4.11 \\
0.13\end{array}$ \\
\hline & Extract & $\begin{array}{l}4 \\
(16.6 \% \\
)\end{array}$ & $\begin{array}{l}3 \\
(12.5 \% \\
)\end{array}$ & $\begin{array}{l}5 \\
(20.83 \%)\end{array}$ & $\begin{array}{l}\mathrm{F} \\
=1.9 \\
0 \\
0.74\end{array}$ \\
\hline
\end{tabular}

X2: Chi square Test

F: Fisher exact test

£: One-way ANOVA

*Statistically significant at $\mathrm{P}$ value $\leq 0.05$

MDZ: Midazolam

DEX: Dexmedetomidine

DEX/MDZ: Dexmedetomidine-Midazolam combination

Table 2: Onset and duration of sedation among study groups

\begin{tabular}{|l|l|l|l|l|}
\hline & MDZ & DEX & $\begin{array}{l}\text { DEX/MD } \\
\text { Z }\end{array}$ & $\begin{array}{l}\text { Test } \\
\text { Value } \\
£ \\
\mathrm{P} \\
\text { Value }\end{array}$ \\
\hline $\begin{array}{l}\text { Onset } \\
\text { time } \\
\text { (min) }\end{array}$ & $\begin{array}{l}11.88 \pm \\
5.48 \mathrm{a}\end{array}$ & $\begin{array}{l}17.08 \\
\pm 5.88 \mathrm{~b}\end{array}$ & $\begin{array}{l}8.33 \\
4.34 \mathrm{a}\end{array}$ & $\begin{array}{l}22.88 \\
<0.00 \\
1^{*}\end{array}$ \\
\hline $\begin{array}{l}\text { Durati } \\
\text { on } \\
\text { time } \\
\text { (min) }\end{array}$ & $\begin{array}{l}38.33 \pm 1 \\
4.5 \mathrm{a}\end{array}$ & $\begin{array}{l}48.33 \pm 15 \\
.3 \mathrm{~b}\end{array}$ & $\begin{array}{l}68.13 \pm 17 \\
.12 \mathrm{c}\end{array}$ & $\begin{array}{l}34.00 \\
<0.00 \\
1^{*}\end{array}$ \\
\hline
\end{tabular}

£: Kruskal - Wallis Test.

* Statistically significant at $\mathrm{P}$ value $\leq 0.05$.

a,b,c Different letters denote statistically significant difference between groups using Bonferroni adjustment for 
multiple comparisons.

MDZ: Midazolam

DEX: Dexmedetomidine

DEX/MDZ: Dexmedetomidine-Midazolam combination

Table 3: Systolic and diastolic blood pressure, heart rate and oxygen saturation throughout the sedation session among study groups:

\begin{tabular}{|c|c|c|c|c|c|}
\hline \begin{tabular}{|l} 
VITA \\
L \\
SIGN \\
S \\
\end{tabular} & & MDZ & DEX & $\begin{array}{l}\mathrm{DEX} / \mathrm{MD} \\
\mathrm{Z}\end{array}$ & $\begin{array}{l}\text { Test } ¥ \\
\mathbf{P} \\
\text { Value }\end{array}$ \\
\hline \multirow{5}{*}{$\begin{array}{l}\text { Mean } \\
\text { SBP } \pm \\
\text { SD }\end{array}$} & Baseline & $\begin{array}{l}102.0 \\
4 \quad \pm \\
10.25\end{array}$ & $\begin{array}{l}103.25 \quad \pm \\
7.02\end{array}$ & $\begin{array}{l}104.54 \pm \\
8.27\end{array}$ & \multirow{5}{*}{$\begin{array}{l}0.45 \\
0.64\end{array}$} \\
\hline & $\begin{array}{l}\text { After 1st } \\
\text { drug dosage }\end{array}$ & $\begin{array}{l}98.13 \\
\pm \\
9.44\end{array}$ & $\begin{array}{l}97.46 \quad \pm \\
6.42\end{array}$ & $\begin{array}{l}100.46 \pm \\
7.72\end{array}$ & \\
\hline & $\begin{array}{l}\text { After 2nd } \\
\text { drug dosage }\end{array}$ & $\begin{array}{l}96.67 \\
\pm \\
8.83\end{array}$ & $\begin{array}{ll}93.33 \quad \pm \\
6.96 & \\
\end{array}$ & $\begin{array}{l}90.67 \quad \pm \\
7.52\end{array}$ & \\
\hline & $\begin{array}{l}\text { Postoperati } \\
\text { ve }\end{array}$ & $\begin{array}{l}100.7 \\
5 \quad \pm \\
9.96\end{array}$ & $\begin{array}{l}102.50 \quad \pm \\
8.90\end{array}$ & $\begin{array}{l}108.17 \pm \\
15.17\end{array}$ & \\
\hline & $\begin{array}{l}\text { Test } ¥ \\
\text { P Value }\end{array}$ & \multicolumn{3}{|c|}{$\begin{array}{l}38.59 \\
<\mathbf{0 . 0 0 1} *\end{array}$} & \\
\hline \multirow{5}{*}{$\begin{array}{l}\text { Mean } \\
\text { DBP } \\
\pm \text { SD }\end{array}$} & Baseline & $\begin{array}{l}65.71 \\
\pm \\
8.63\end{array}$ & $\begin{array}{ll}69.54 & \pm \\
7.18 & \end{array}$ & & \multirow{4}{*}{$\begin{array}{l}1.21 \\
0.31\end{array}$} \\
\hline & $\begin{array}{l}\text { After 1st } \\
\text { drug dosage }\end{array}$ & $\begin{array}{l}62.96 \\
\pm \\
7.68\end{array}$ & $\begin{array}{l}66.63 \quad \pm \\
6.75\end{array}$ & $\begin{array}{l}63.42 \\
6.10\end{array}$ & \\
\hline & $\begin{array}{l}\text { After 2nd } \\
\text { drug dosage }\end{array}$ & $\begin{array}{l}61.00 \\
\pm \\
6.37\end{array}$ & $\begin{array}{l}63.83 \quad \pm \\
7.30\end{array}$ & $\begin{array}{l}58.21 \quad \pm \\
5.12\end{array}$ & \\
\hline & $\begin{array}{l}\text { Postoperati } \\
\text { ve }\end{array}$ & $\begin{array}{l}64.71 \\
\pm \\
7.82\end{array}$ & $\begin{array}{l}64.63 \\
6.45\end{array}$ & $\begin{array}{l}68.04 \quad \pm \\
9.56\end{array}$ & \\
\hline & $\begin{array}{l}\text { Test } ¥ \\
\text { P Value }\end{array}$ & $\begin{array}{l}22.37 \\
<\mathbf{0 . 0 0 1}\end{array}$ & & & \\
\hline \multirow{5}{*}{$\begin{array}{l}\text { Mean } \\
\text { HR } \pm \\
\text { SD }\end{array}$} & Baseline & $\begin{array}{l}103.1 \\
3 \pm \\
9.45\end{array}$ & & 9.95 & \multirow{4}{*}{$\begin{array}{l}25.56 \\
<\mathbf{0 . 0 0 1} \\
*\end{array}$} \\
\hline & $\begin{array}{l}\text { After 1st } \\
\text { drug dosage }\end{array}$ & $\begin{array}{l}95.58 \\
\pm \\
6.76\end{array}$ & & & \\
\hline & $\begin{array}{l}\text { After 2nd } \\
\text { drug dosage }\end{array}$ & $\begin{array}{l}91.58 \\
\pm \\
10.45\end{array}$ & $\begin{array}{l}67.46 \\
7.39\end{array}$ & $\begin{array}{l}69.25 \quad \pm \\
12.88\end{array}$ & \\
\hline & $\begin{array}{l}\text { Postoperati } \\
\text { ve }\end{array}$ & $\begin{array}{l}98.38 \\
\pm \\
18.73\end{array}$ & $\begin{array}{l}72.29 \\
12.85\end{array}$ & $\begin{array}{l}101.00 \\
\pm 19.63\end{array}$ & \\
\hline & $\begin{array}{l}\text { Test } ¥ \\
\text { P Value }\end{array}$ & \multicolumn{2}{|c|}{$\begin{array}{l}14.88 \\
<\mathbf{0 . 0 0 1} \text { * }\end{array}$} & & \\
\hline \multirow{4}{*}{$\begin{array}{l}\text { Mean } \\
\text { SaO2 } \\
\pm \text { SD }\end{array}$} & Baseline & $\begin{array}{l}97.92 \\
\pm \\
1.25\end{array}$ & $\begin{array}{l}96.83 \\
2.68\end{array}$ & $\begin{array}{ll}97.58 \quad \pm \\
1.25\end{array}$ & \multirow{4}{*}{$\begin{array}{l}0.30 \\
0.74\end{array}$} \\
\hline & $\begin{array}{l}\text { After 1st } \\
\text { drug dosage }\end{array}$ & $\begin{array}{l}97.75 \\
\pm \\
1.51\end{array}$ & $\begin{array}{l}97.79 \quad \pm \\
1.32\end{array}$ & $\begin{array}{l}97.25 \quad \pm \\
1.82\end{array}$ & \\
\hline & $\begin{array}{l}\text { After 2nd } \\
\text { drug dosage }\end{array}$ & $\begin{array}{l}97.83 \\
\pm \\
1.09\end{array}$ & $\begin{array}{ll}97.63 \quad \pm \\
1.58\end{array}$ & $\begin{array}{l}97.96 \quad \pm \\
1.40\end{array}$ & \\
\hline & $\begin{array}{l}\text { Postoperati } \\
\text { ve }\end{array}$ & $\begin{array}{l}97.54 \\
\pm \\
1.38\end{array}$ & $\begin{array}{l}97.92 \quad \pm \\
1.10\end{array}$ & $\begin{array}{l}97.71 \quad \pm \\
1.76\end{array}$ & \\
\hline
\end{tabular}

\begin{tabular}{|l|l|l|l|}
\hline & Test $¥$ & 0.91 & \\
& P Value & 0.42 & \\
\hline
\end{tabular}

$¥:$ Repeated measures ANOVA

*Statistically significant at $\mathrm{P}$ value $\leq 0.05$

MDZ: Midazolam

DEX: Dexmedetomidine

DEX/MDZ: Dexmedetomidine-Midazolam combination

\section{DISCUSSION:}

Moderate sedation is used as an adjunct to basic behavior management techniques to control children's anxiety during dental sessions. Sedation using MDZ, DEX, and DEX/MDZ were found to be safe and effective during dental treatment for preschool children. Dental behavioral problems are the most common obstacle for treating pediatric dental patients. Most preschool children do not co-operate in the dental clinic (19), as they are less able to express their fears and anxieties (2). Gaining the child's cooperation during dental procedure is challenging, and requires various behavioral management strategies (29). Midazolam had always been the favored drug for pediatric dental sedation, because of its relative safety at therapeutic doses (25). However, DEX use in moderate sedation had been gaining momentum, for its sedative, anxiolytic and analgesic effect (6). In the year 2017,Cozzi et al. (30) suggested that DEX was a safe sedative for children and infants since it has sympatholytic properties, it induces minimal respiratory depression and mild effect on heart rate. The combination of sedative agents should be viewed as a balancing technique to produce a maximum result with minimum risk of complication (25). The use of combination of DEX and MDZ for children had shown an increase in the efficacy of $\mathrm{DEX}$ and decreasing the risk of respiratory depression that might be associated with MDZ (30).

The early onset of sedation and its maintenance till safe recovery are important characteristics of sedative agents (31). In the present study, the combination of DEX/MDZ had the most rapid onset and the longest duration of action among either MDZ or DEX groups. Children who were sedated with DEX had a significant delay in onset of sedation than those sedated by either MDZ or DEX/MDZ. That was in accordance with other studies who stated that one disadvantage of intranasal DEX when compared with MID was the relatively slow onset of effect (14, 31, 32).

As for the duration of sedation, there were significant differences between the three groups, where MDZ had the shortest duration and DEX/MDZ had the longest duration of action. The combination between the two sedative drugs benefits from synergistic effect of both; as MDZ has the rapid onset of action while DEX has a more prolonged effect. The slower onset of sedation with DEX may be due to the lag time required to reach peak plasma concentration specially with small doses, that was proved in a study by Yoo et al. (33), that following intranasal administration of DEX in healthy volunteers, the time to maximum plasma concentration had been reached $38 \mathrm{~min}$ after administration. While the lipophilic property of MDZ make it reach the brain quickly with a distribution half-life of 6-15 minutes after administration (11). Similarly, Sheta et 
al. (14), and Colin et al. (35) concluded that MDZ could be suitable for short-lasting procedures. Thus, the use of MDZ might be more beneficial for sedating patients in busy outpatient clinics.

In present study mild alterations in vital signs were reported but no clinical intervention was required. This was in accordance with previous studies $(6,14,34)$. As observed, the changes occurred within vital signs were dependent on drug dosage. Previously, Colin et al. (34), proved that DEX sedative and vital signs are highly correlated. For heart rate, a straightforward correlation was detected with the sedative effects, while the relationship between blood pressure and the sedative effects was less straight forward (34). The effect of DEX on blood pressure is a biphasic effect with transient hypertension followed by hypotension $(14,29,31)$. The transient hypertension can be avoided with a slow increase in concentration $(6,9)$. This might explain the reason why there was no hypertension detected among the participants, since the nebulizer allowed for slow administration of drug and so avoided a sudden high plasma concentration. In the present study, blood pressure slightly decreased with DEX administration, but no increase in blood pressure was observed. Therefore, the slow administration of DEX is beneficial to avoid unwanted blood pressure changes (29). However, Mountain et al. (35), indicated that administration of up to $4 \mu \mathrm{g} / \mathrm{kg}$ DEX would only result in hypotension and bradycardia. This is related to the sympatholytic effect of DEX. It had been proved that the decrease in heart rates with DEX are dose dependent as well (36) , that proves the significant difference detected between DEX and DEX/MDZ group.

Using high doses of DEX provided adequate sedation associated with decrease in heart rate and blood pressure within a normal range of deviation, and was not associated with adverse events. (36) Similarly, Maaly et al. (37),

comparing the hemodynamic parameters of MDZ and DEX i $\mathrm{n}$ infants found that DEX resulted in decreased heart rate and blood pressure. In contrast to the findings of the current study, Sheta et al. (14), reported no changes in neither heart rate nor blood pressure with DEX, while Greaves et al. (24), and Togawa et al. (38), reported that MDZ caused vital signs stability. However, in current study, MDZ had caused mild decrease in both BP and HR compared to DEX regimens ( DEX, DEX/MID).

Oxygen saturation levels were stable among all children participated in the present study during the whole session of sedation either with MDZ, DEX, or their combination. As stated with Barends (6), MDZ has the potential to cause loss of airway reflexes, a nd breathing distress, while DEX does not impair the respiratory drive. In contrast, low oxygen saturation levels had been reported after DEX administration by Tobias and Leder (39), that did not require any clinical intervention.

On overall assessment it was found that MID, $\mathrm{DEX}$, and their combination are safe drugs to be used during dental treatment for preschool children. However, DEX has moderately slow pharmacokinetics in comparison to MID, and so its delayed onset and recovery time, make it unsuitable for short procedures. One of the limitation in the present study was the division of the calculated dosage for each child into two to keep the blindness, which prolonged the administration time and might had affected the plasma concentration of sedative drug. According to findings of the current study the null hypothesis was rejected.

\section{CONCLUSION}

It was concluded that MDZ, DEX, and their combination are safe for use during in moderate sedation for preschool children, to enhance the child's comfort and control anxiety during dental treatment. However, the use of Midazolam might be more beneficial for short procedures carried out in busy outpatient centers, but the use of Dexmedetomidine or a combination of Dexmedetomidine and Midazolam is more effective for long extensive dental treatment.

CONFLICT OF INTEREST

The authors declare that they have no conflicts of interest. ACKNOWLEDGMENT

I would like to thank all children and their families who participated in the study.

\section{REFERENCES}

1. Zanaty OM, El Metainy SA. A comparative evaluation of nebulized dexmedetomidine, nebulized ketamine, and their combination as premedication for outpatient pediatric dental surgery. Anesth Analg. 2015;121:167-71.

2. Gupta A MC, Bhatia HP, Dahiya V. Behaviour management of an anxious child. Stomatologija. 2014;16:3-6.

3. Silva CC LC, Areias C, Moura ${ }^{\sim}$ o J, Andrade D. . Conscious sedation vs general anesthesia in pediatric dentistry - a review. MedicalExpress (São Paulo, online). . 2015;2:M150104

Doi.org/10.5935/MedicalExpress.2015.01.04

4. AAoPD. CAC-BMS. Guideline on Behavior Guidance for the Pediatríc Dental Patient. Pediatr Dent. 2015 37:57-70.

5. Attri JP, Sharan R, Makkar V, Gupta KK, Khetarpal R, Kataria AP. Conscious Sedation: Emerging Trends in Pediatric Dentistry. Anesth Essays Res. 2017;11:277-81.

Barends CR AA, van Minnen B, Vissink A, Visser A. Dexmedetomidine versus Midazolam in Procedural Sedation. A Systematic Review of Efficacy and Safety. PLoS One. 2017;12:e0169525. DOI: 10.1371/journal.pone.0169525

7. Ghajari MF AG, Hasanbeygi L, Shayeghi S. Conscious Sedation Efficacy of 0.3 and $0.5 \mathrm{mg} / \mathrm{kg}$ Oral Midazolam for Three to Six Year-Old Uncooperative Children Undergoing Dental Treatment: A Clinical Trial. J Dent (Tehran). 2016;13:101-7.

8. Ghai B JK, Saxena AK, Bhatia N, Sodhi KS. Comparison of oral midazolam with intranasal dexmedetomidine premedication for children undergoing CT imaging: a randomized, double-blind, and controlled study. Paediatr Anaesth. 2017;27:37-44.

9. Weerink MAS SM, Hannivoort LN, Barends CRM, Absalom AR, Colin P. Clinical Pharmacokinetics and Pharmacodynamics of Dexmedetomidine. Clin Pharmacokinet. 2017;56:893-913.

10. Singh C, Pandey RK, Saksena AK, Chandra G. A comparative evaluation of analgo-sedative effects of oral 
dexmedetomidine and ketamine: a triple-blind, randomized study. Paediatr Anaesth. 2014;24:1252-9.

11. Bagheri M. The Use of Midazolam in Paediatric Dentistry: A Review of the Literature. Razavi Int J Med. 2014;2:e16913. DOI: 10.5812/rijm.16913

12. Kumari S, Agrawal N, Usha G, Talwar V, Gupta P. Comparison of Oral Clonidine, Oral Dexmedetomidine, and Oral Midazolam for Premedication in Pediatric Patients Undergoing Elective Surgery. Anesth Essays Res. 2017;11:185-91.

13. Oriby ME. Comparison of Intranasal Dexmedetomidine and Oral Ketamine Versus Intranasal Midazolam Premedication for Children Undergoing Dental Rehabilitation. Anesth Pain Med. 2019;9:e85227. DOI: 10.5812/aapm.85227

14. Sheta SA, Al-Sarheed MA, Abdelhalim AA. Intranasal dexmedetomidine vs midazolam for premedication in children undergoing complete dental rehabilitation: a double-blinded randomized controlled trial. Paediatr Anaesth. 2014;24:181-9.

15. Wakita R, Kohase H, Fukayama H. A comparison of dexmedetomidine sedation with and without midazolam for dental implant surgery. Anesth Prog. 2012;59:62-8.

16. Moher D HS, Schulz KF, Montori V, Gøtzsche PC, Devereaux PJ, Elbourne D, Egger M, Altman DG. BMJ 2010;340:c869Research Methods and Reporting: CONSORT 2010 Explanation and Elaboration: updated guidelines for reporting parallel group randomised trials. BMJ 2010;340:c869. 2010.

17. Faul F, Erdfelder, E., Lang, A.-G., \& Buchner, A. $\mathrm{G}^{*}$ Power 3: A flexible statistical power analysis program for the social, behavioral, and biomedical sciences. Behavior Research Methods. 2007;39:175-91.

18. ASA Physical Status Classification System. Available at: https://www.asahq.org/resources/clinical-information/asaphysical-status-classification-system. American Society of Anesthesiologists. Accessed on 20 JUN 2018

19. Singh H RR, Kadtane S, Dalai DR, Jain CD. Techniques for the Behavior Management in Pediatric Dentistry. Int J Sci Stud 2014;2:269-72.

20. Frankl SN SF, Fozels HR. Should the parent remain with the child in the dental operatory? J Dent Child 1962;29:150-63.

21. Gomes HS MA, Viana KA, Batista AC, Costa PS, Daher A, Machado GC, Sado-Filho J VL, Corrêa-Faria P, Hosey MT, Costa LR. Intranasal sedation using ketamine and midazolam for pediatric dental treatment (NASO): study protocol for a randomized controlled trial. Trials. 2017;18:172. Doi: 10.1186/s13063-017-1919-2

22. Guideline for Monitoring and Management of Pediatric Patients Before, During, and After Sedation for Diagnostic and Therapeutic Procedures: Update 2016. Pediatr Dent. 2016;15:77-106.

23. Jambure $\mathrm{N}$ NA. Comparison of Intranasal dexmedetomidine and oral midazolam as premedication for cardiac catheterization procedure in pediatric patients. Anaesth Pain \& Intensive Care. 2016;20(Suppl 1:S48S52).Doi: 10.4103/aer.AER_119_17

24. Greaves A. The use of Midazolam as an Intranasal Sedative in Dentistry. SAAD Dig. 2016;32:46-9.
25. Dean J, Jones, J., Vinson, L. and McDonald, R. Saxen A. pharmacological behaviour managment. McDonald and Avery's dentistry for the child and adolescent. St. Louis, Missouri: Elsevier. 2016:303-27.

26. Wilton NC LJ RD, Pandit UA. Preanesthetic sedation of preschool children using intranasal midazolam. Anesthesiol. 1988;69:972-5.

27. Canpolat DG YM, Aksu R, Kutuk N, Alkan A, Cantekin $\mathrm{K}$. Intravenous ketamine, propofol and propofol-ketamine combination used for pediatric dental sedation: A randomized clinical study. Pak J Med Sci. 2016;32:682-7.

28. Li BL ZN, Huang JX, Qiu QQ, Tian H, Ni J, Song XR, Yuen VM, Irwin MG. A comparison of intranasal dexmedetomidine for sedation in children administered either by atomiser or by drops. Anaesthesia. 2016;71:5228.

29. Mohite V, Baliga S, Thosar N, Rathi N. Role of dexmedetomidine in pediatric dental sedation. J Dent Anesth Pain Med. 2019;19:83-90.

30. Cozzi G ML, Maximova N, Poropat F, Magnolato A, Sbisà E, Norbedo S, Sternissa G ZD, Barbi E. Combination of intranasal dexmedetomidine and oral midazolam as sedation for pediatric MRI. Paediatr Anaesth. 2017;27:976-7.

31. Surendar MN, Pandey RK, Saksena AK, Kumar R, Chandra G. A comparative evaluation of intranasal dexmedetomidine, midazolam and ketamine for their sedative and analgesic properties: a triple blind randomized study. J Clin Pediatr Dent. 2014;38:255-61.

32. Mahdavi A, Fallahinejad Ghajari M, Ansari G, Shafiei L. Intranasal Premedication Effect of Dexmedetomidine Versus Midazolam on the Behavior of 2-6-Year-Old Uncooperative Children in Dental Clinic. J Dent (Tehran). 2018;15:79-85.

33. Yoo H, Iirola T, Vilo S, Manner T, Aantaa R, Lahtinen M, et al. Mechanism-based population pharmacokinetic and pharmacodynamic modeling of intravenous and intranasal dexmedetomidine in healthy subjects. Eur J Clin Pharmacol. 2015;71:1197-207.

34. Colin PJ, Hannivoort LN, Eleveld DJ, Reyntjens K, Absalom AR, Vereecke HEM, et al. Dexmedetomidine pharmacodynamics in healthy volunteers: 2. Haemodynamic profile. Br J Anaesth. 2017;119:211-20.

35. Mountain BW, Smithson L, Cramolini M, Wyatt TH, Newman M. Dexmedetomidine as a pediatric anesthetic premedication to reduce anxiety and to deter emergence delirium. AANA J. 2011;79:219-24.

36. Frolich MA, Arabshahi A, Katholi C, Prasain J, Barnes S. Hemodynamic characteristics of midazolam, propofol, and dexmedetomidine in healthy volunteers. J Clin Anesth. 2011;23:218-23.

37. Maaly AM HA, El Neily DA, Hamouda SA, Abdel-Razek A. Effect of premedication with clonidine, midazolam, and dexmedetomidine on stress response and sedation in pediatric congenital cardiac surgeries. Res Opin Anesth Intensive Care 2019;6:321-9.

38. Togawa E, Hanamoto H, Maegawa H, Yokoe C, Niwa H. Dexmedetomidine and Midazolam Sedation Reduces Unexpected Patient Movement During Dental Surgery 
Compared With Propofol and Midazolam Sedation. J Oral

Maxillofac Surg. 2019;77:29-41.

39. Tobias JD, Leder M. Procedural sedation: A review of sedative agents, monitoring, and management of complications. Saudi J Anaesth. 2011;5:395-410.

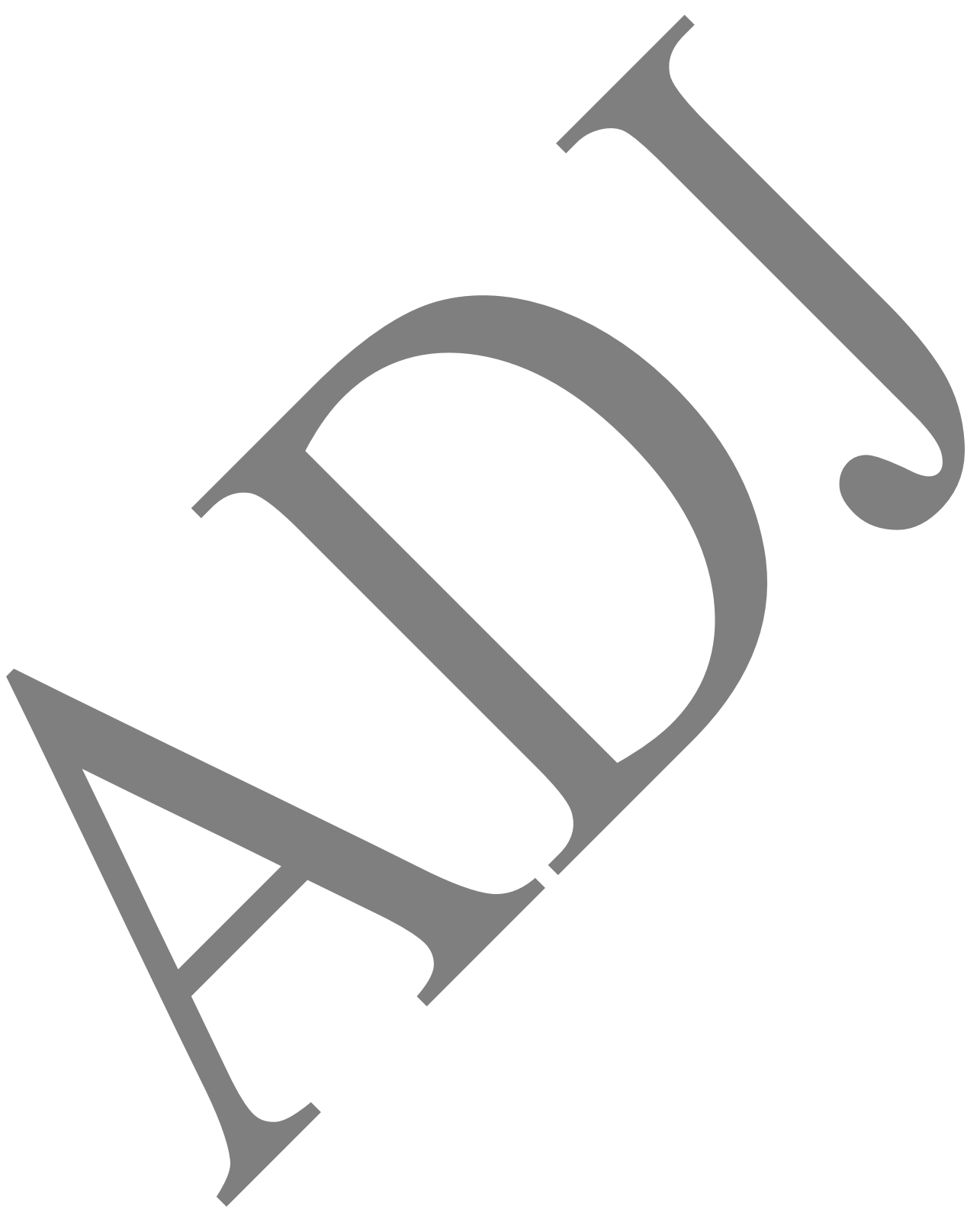

